\title{
Combined Effects of Sustained Loads and Wet-Dry Cycles on Durability of Glass Fiber Reinforced Polymer Composites
}

\author{
Mengting Li, ${ }^{1}$ Jun Wang, ${ }^{1}$ Weiqing Liu, ${ }^{1}$ Ruifeng Liang, ${ }^{2}$ Hota GangaRao, ${ }^{2}$ and Yang Li \\ ${ }^{1}$ College of Civil Engineering, Nanjing Tech University, Nanjing 211816, China \\ ${ }^{2}$ Department of Civil and Environmental Engineering, West Virginia University, Morgantown, WV, USA \\ ${ }^{3}$ Jiangsu Wei Xin Engineering Consultants Ltd., Nanjing, China \\ Correspondence should be addressed to Jun Wang; wangjun3312@njtech.edu.cn and Weiqing Liu; wqliu@njtech.edu.cn
}

Received 20 June 2017; Accepted 11 September 2017; Published 23 October 2017

Academic Editor: Fabrizio Sarasini

Copyright (C) 2017 Mengting Li et al. This is an open access article distributed under the Creative Commons Attribution License, which permits unrestricted use, distribution, and reproduction in any medium, provided the original work is properly cited.

\begin{abstract}
This paper deals with durability of glass fiber reinforced polymer (GFRP) composites under the combined effects of sustained tensile loads and wet-dry (WD) cycles. Two different solutions (distilled water and saltwater) were used to imitate the freshwater and marine environments, respectively. Tensile properties of the unconditioned and conditioned specimens were measured to study the durability of GFRP composites under these 2 effects. The response indicated that both tensile strength and elastic modulus increased initially upon WD cycles, which was attributed to both the postcuring of resin and the sustained tensile stress allowing for fastec cure. Further exposure to WD cycles in distilled water or saltwater led to a steady decrease in tensile strength and modulus. WD cycles of saltwater and distilled water have similar effects on the degradation of the tensile properties for unstressed specimens. However, the elastic modulus and elongation at rupture of stressed specimens under WD cycles of saltwater decreased more than those specimens under WD cycles of distilled water. Moreover, increase of sustained loads led to a decrease in tensile strength. Based on Arrhenius method, a prediction model which accounted for the effects of postcure processes was developed. The predicted results of tensile strength and elastic modulus agree well with those obtained from the experiments.
\end{abstract}

\section{Introduction}

The use of fiber reinforced polymer (FRP) composites in the construction of waterfront and marine infrastructures has been increasing rapidly, due to their advantage of light weight, high tensile strength, and better reinforce to aqueous corrosion. Because of economic benefits in construction, glass fiber reinforced polymer (GFRP) composites are becoming prevalent in civil engineering structures. FRP structures are usually exposed to harsh in-service environment, such as moisture, corrosive media, sustained stress, temperature, and ultraviolet radiation. Cyclic moisture effect near the splash-zone of marine structures is one of the important environmental factors to deteriorate the properties and behavior of polymer matrix composites [1]. Moreover, the environmental attack is combined with sustained loading prone to aggravate the deterioration of GFRP. Therefore, better understanding of the long-term behavior of GFRP under the combined effects of load and moisture cycles is helpful to promote its applications.
In recent decades, several researchers have investigated durability issues of FRP reinforced concrete (RC) structures subjected to wet-dry (WD) cycles. Soudki et al. [2] studied the behavior of CFRP strengthened RC beams subjected to WD cycles with $3 \% \mathrm{NaCl}$. Their test results displayed that the critical chloride levels reached the reinforced steel bars after 200 WD cycles and visible cracks and stains appeared after 300 WD cycles. Belarbi and Bae [3] evaluated the combined effects of freeze-thaw (FT) cycles and WD cycles on the long-term behavior of RC columns strengthened with CFRP and GFRP sheets. Their studies indicated that, after 300 FT cycles, the failure load and axial stiffness of both CFRP and GFRP strengthened RC columns increased slightly due to the matrix hardening effects at extremely low temperatures. The combined FT and WD cycles have insignificant effects on mechanical properties of CFRP wrapped RC columns, while the failure loads of GFRP wrapped RC columns decreased remarkably. These results are in good agreement 
with former findings reported by Toutanji and EI-Korchi [4]. Yin et al. [5] investigated the mechanical properties and durability of RC columns strengthened by hybrid carbon and E-glass fiber/epoxy textile. It showed that, under the coupled effects of WD cycles and sustained stress, the bearing capacity and ductility of the columns and the reinforcement effects of textile decreased more rapidly as the sustained compression stress increased. Moreover, exposure to chloride WD cycles generated corrosive products $\left(\mathrm{C}_{3} \cdot \mathrm{CaCl}_{2} \cdot 10 \mathrm{H}_{2} \mathrm{O}\right)$ on the interface between textile and concrete.

One of the major challenges to be addressed for FRP wrapped concrete is the long-term durability of externally bonded FRP [6, 7]. A number of experimental programs have been conducted to examine the behavior of FRPconcrete interface subjected to WD cycles. Silva and Biscaia [8] investigated the durability of RC beams reinforced with GFRP strips under different conditions (temperature cycles, WD cycles, complete immersion in water, and salt fogging cycles, for up to $1000 \mathrm{~h}$ ). Their test results showed that the temperature cycles $\left(-10\right.$ to $\left.+10^{\circ} \mathrm{C}\right)$ were the most severe condition on the bending strength, followed by the salt fog cycles, while total immersion in water was the most severe condition on the pull-off strength, followed by WD cycles and salt fogging cycles. For CFRP bonded concrete columns, WD cycles (one-week wetting at 95\% RH and $30-32^{\circ} \mathrm{C}$ followed by one-week drying at $20-23^{\circ} \mathrm{C}$ ) were the most severe condition on fracture energy compared with temperature cycles $\left(30\right.$ to $40^{\circ} \mathrm{C}$ ) and outdoor environment [9]. Kim et al. [10, 11] investigated the interfacial behavior of CFRP composite sheets bonded to concrete blocks subjected to freezing-wet-dry cycles and WD cycles, respectively. The results showed that the effects of freezing-wet-dry cycles were more detrimental than those of WD cycles on the behavior of CFRP-concrete interface, especially when the temperature was below $-20^{\circ} \mathrm{C}$. Biscaia et al. [12] examined the interface of GFRP and concrete subjected to salt fog cycles and WD cycles with saltwater. A $27 \%$ reduction of cohesion was found after 416 salt fog cycles and $8 \%$ reduction of the friction angle was found after 60 WD cycles due to the water attack at the interface. Wang and Amidi [13] applied environment-assisted subcritical debonding testing (EASD) program to evaluate the long-term durability of the CFRP-to-concrete interface subjected to the coupled effects of mechanical load, humidity, and temperature. They found that silane coupling agent could improve the durability of the CFRP-to-concrete interface due to introducing covalent bonds between the epoxy and concrete. Lipatov et al. [14] reported that the adding zirconia to basalt fibers contributed to improving the durability of fibers in alkali solution, and basalt fibers with $5.7 \mathrm{wt} \% \mathrm{ZrO}_{2}$ had the best alkali resistance properties.

With the development of novel FRP structural members in recent years [15], some researchers start to pay attention to the durability of new FRP construction $[16,17]$. Toutanji and Saafi [18] proposed a new hybrid concrete column consisting of an exterior PVC-FRP shell with a concrete core. The compressive test showed that the PVC-CFRP confined concrete columns performed well when subjected to FT and WD cycles, whereas the PVC-GFRP and PVC-AFRP confined concrete columns experienced significant reductions in both strength and ductility after 400 FT and 400 WT cycles. Chen et al. [19] evaluated the durability of FRP reinforcing bars for concrete structures from accelerated aging tests. It showed that continuous immersion in solutions with a $\mathrm{pH}$ value of 13.6 resulted in greater degradation than exposure to WD cycling for GFRP bars, while FT cycles had insignificant effects on the strength of GFRP bars.

Most of FRP structures are designed to resist some level of sustained load in-service engineering. The combination of environmental attacks with sustained stress can aggravate the loss of mechanical properties of FRP composites [20, 21]. Myers et al. [22] investigated the coupled effects of environmental attacks (FT cycles, moisture, high temperature cycling, and indirect ultraviolet radiation exposure) and sustained loads on the performance of interface between FRP and concrete. It is observed that the bond property of specimens under sustained load ( $40 \%$ of ultimate load) degraded greater than that of unstressed specimens in the same environment. Mahato et al. [23] studied the tensile behavior of GFRP composites under the coupled effects of temperature and loads. The tensile strength of the GFRP composites was observed to increase with the enhancement of loading speeds, and exposure in different temperature environments $\left(25^{\circ} \mathrm{C}\right.$ to $\left.110^{\circ} \mathrm{C}\right)$ resulted in little change in glass transition temperatures $\left(T_{g}\right)$. The authors [24] investigated GFRP durability under combined effects of moisture and sustained loads and found that the tensile properties of GFRP decreased significantly as the sustained loading increased under salt water for 360 days, whereas GFRP specimens with and without sustained loads had little changes in tensile properties under tap water.

Although many focused on single or coupled effects of environmental attacks under sustained loads in several studies, the durability of FRP composites under the combined effects of WD cycles and sustained loads has received scant attention. The coupled effects cannot be simplified by simply superposing the responses under different environmental attacks, and the mechanisms of degradation under single environmental attack are far different when compared with those under combined environmental attacks. This paper is concerned with investigating the long-term behavior of GFRP composites subjected to the combined effects of tensile loads and WD cycles. Microstructural and physical observations were performed to examine the conditioned and unconditioned samples. Moreover, a theoretical model was developed to predict the tensile properties of GFRP composites based on Arrhenius method.

\section{Experimental Program}

2.1. Materials. The test specimens were reinforced with bidirection $\left(0^{\circ} / 90^{\circ}\right)$ E-glass plain woven fabric provided by Sinoma Nanjing Fiberglass Research \& Design Institute. The fabric had an average thickness of $0.5 \mathrm{~mm}$ and a unit weight of $500 \mathrm{~g} / \mathrm{m}^{2}$. Isophthalic polyester resin (Synolite 0593-I-3) supplied by DSM China was used as matrix. $3 \mathrm{wt} \%$ cyclohexanone peroxide and $2 \mathrm{wt} \%$ cobalt isocaprylate-styrene were used as the initiator and acceleration employed for isophthalic polyester resin curing. 


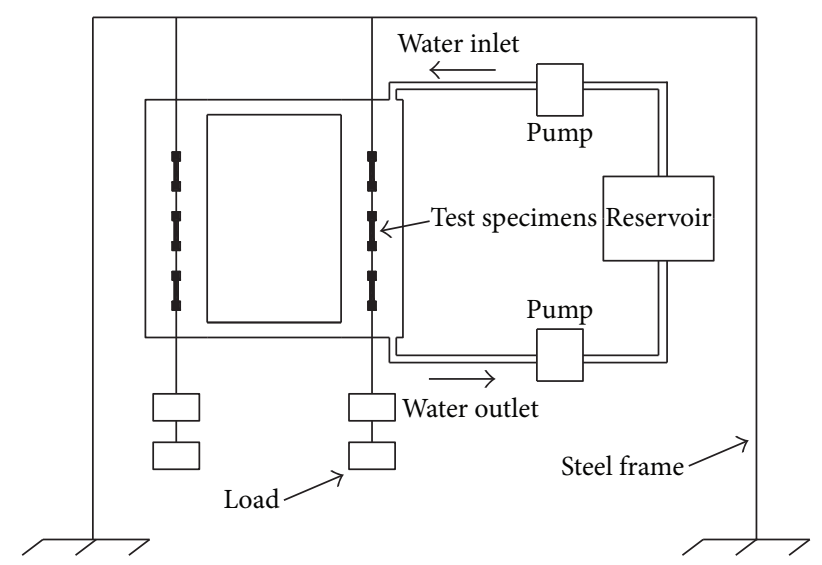

FIGURE 1: Schematic of the wet-dry exposure set-up.

A flat $1 \mathrm{~m} \times 2 \mathrm{~m}$ panel with a thickness of $2 \mathrm{~mm}$ was fabricated using resin infusion under flexible tooling (RIFT2) method and cut to coupons of $250 \mathrm{~mm} \times 20 \mathrm{~mm} \times 2 \mathrm{~mm}$ size. In addition, a surface layer of resin was applied to seal the specimens. The fiber volume fraction for the GFRP composites was about $60 \%$. The specimens were cured at room temperature for 3 days, and then were cured in an oven at $60^{\circ} \mathrm{C}$ for 3 hours.

2.2. Apparatus. Figure 1 shows the environmental exposure set-up. The specimens were exposed to two environments: (1) WD cycles of distilled water; (2) WD cycles of saltwater with a salinity content of about 3.5\%. Each cycle consisted of full immersion in water for 12 hours followed by air drying for 12 hours at room temperature. The numbers of cycles for the GFRP composites were 15, 30, 60, 90, 180, and 360, respectively. The applied stresses chosen for the specimens were $0 \%, 20 \%$, and $40 \%$ of the tensile strength of the GFRP composites, respectively. Three duplicate specimens were connected in series and were tensioned by the weights of concrete. Both ends of the specimens were reinforced by $50 \mathrm{~mm} \times 20 \mathrm{~mm} \times 5 \mathrm{~mm}$ aluminum tab attachments. The water used to immerse the specimens was controlled by pumps. In the drying condition, the extra water was drawn back into the reservoir, while in the wetting condition, the water was poured into the specimen containers.

2.3. Tensile Tests. After conditioning, tensile tests were conducted, in accordance with ASTM D638-10 [25] to collect the tensile strength, elastic modulus, and tensile elongation at the rupture of GFRP composites under different cycles. A universal test machine with $50 \mathrm{kN}$ capacity was used for all specimens, as shown in Figure 2. The tensile load was applied through a stiff steel clamp and was recorded via a load cell mounted directly above the top steel clamp. Before testing, the average cross-sectional area of each specimen was measured. The strain values of the specimens were measured by an extensometer with $25.4 \mathrm{~mm}$ gage length which was connected to the middle of the specimens. Each specimen was stressed to about $50 \%$ of the tensile strength to obtain the elastic modulus, and then the extensometer was removed before

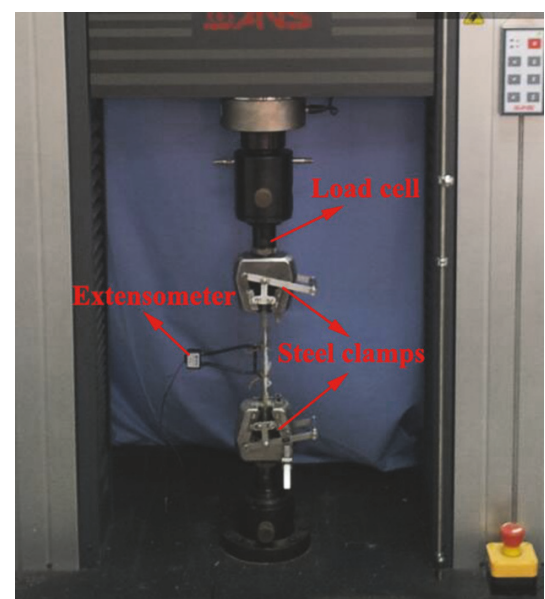

Figure 2: Tensile test set-up.

TABLE 1: Mechanical properties of GFRP under WD cycles.

\begin{tabular}{lcccc}
\hline Specimens & $\begin{array}{c}\text { WD } \\
\text { cycles }\end{array}$ & $\begin{array}{c}\text { Tensile } \\
\text { strength } \\
(\mathrm{MPa})\end{array}$ & $\begin{array}{c}\text { Elastic } \\
\text { modulus } \\
(\mathrm{GPa})\end{array}$ & $\begin{array}{c}\text { Elongation } \\
(\mathrm{mm})\end{array}$ \\
\hline \multirow{6}{*}{ WWD0 } & 0 & 416.75 & 24.70 & 1.813 \\
& 15 & 457.40 & 26.77 & 1.003 \\
& 30 & 448.47 & 26.95 & 1.123 \\
& 90 & 431.72 & 25.87 & 0.834 \\
& 180 & 420.36 & 25.43 & 0.725 \\
& 360 & 370.85 & 23.89 & 0.534 \\
& 0 & 416.75 & 20.86 & 0.515 \\
\hline \multirow{5}{*}{ SWD0 } & 15 & 480.32 & 24.70 & 1.813 \\
& 30 & 442.68 & 27.08 & 1.370 \\
& 60 & 436.58 & 26.57 & 1.014 \\
& 90 & 422.58 & 25.74 & 0.739 \\
& 180 & 411.04 & 24.42 & 0.452 \\
& 360 & 368.66 & 21.85 & 0.474 \\
\hline
\end{tabular}

specimen was stressed to failure. The failure load was used to calculate the tensile strength of the GFRP composites in MPa.

2.4. Microstructural Observations. Electron microscopy (EM) observations and image analysis were performed to examine microstructure of specimens before and after conditions with DM4000M (Leica, Germany). The samples included unconditioned specimens and conditioned specimens after 60 and 180 cycles under different sustained loads. All specimens were first cut and polished before observations. These observations were made on surfaces and sections parallel to the fiber layers for potential degradation of the glass fibers, resin, or interfaces.

\section{Results and Discussion}

3.1. Specimens without Sustained Load. Tensile tests were conducted on GFRP composites subjected to $0,15,60,90$, 180 , and 360 WD cycles of both distilled water and saltwater. Table 1 shows the mechanical properties of GFRP under WD 


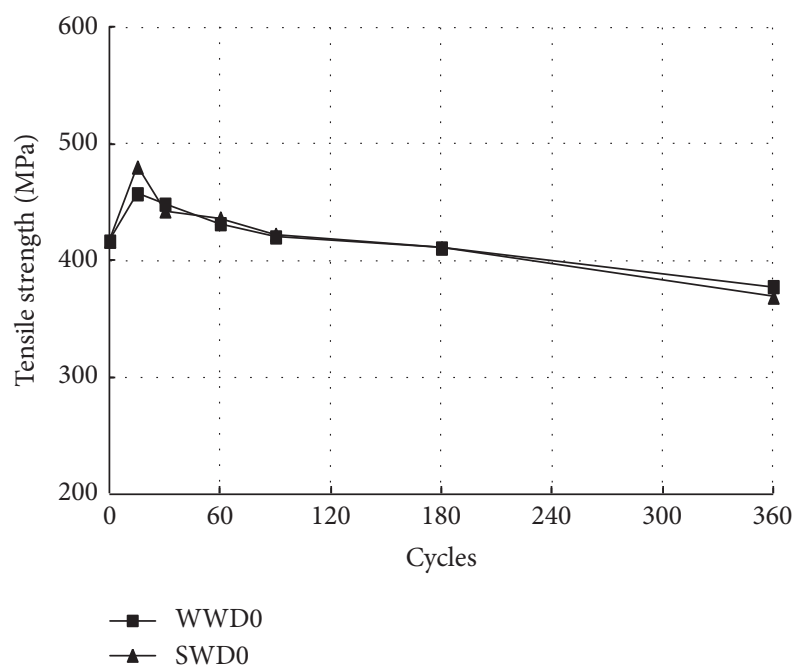

(a)

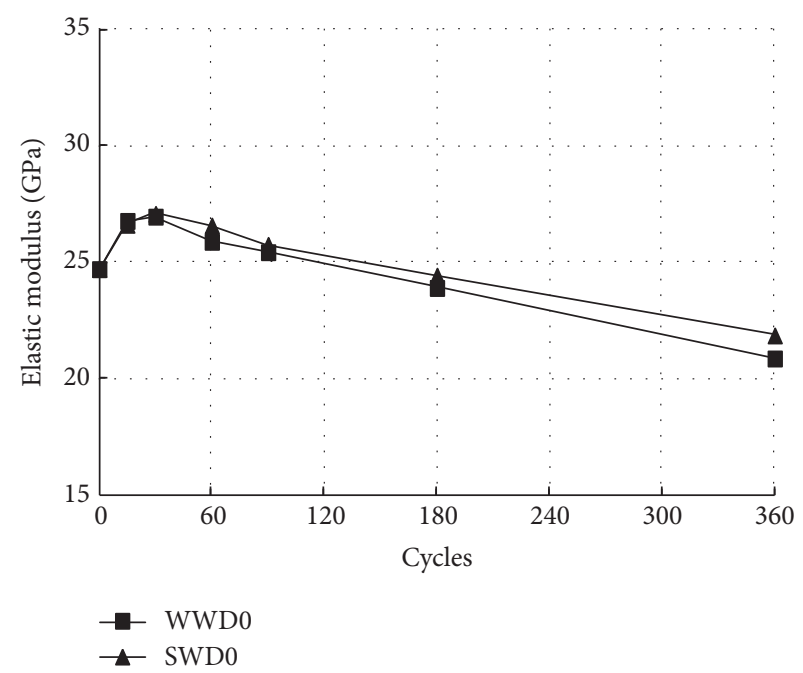

(b)

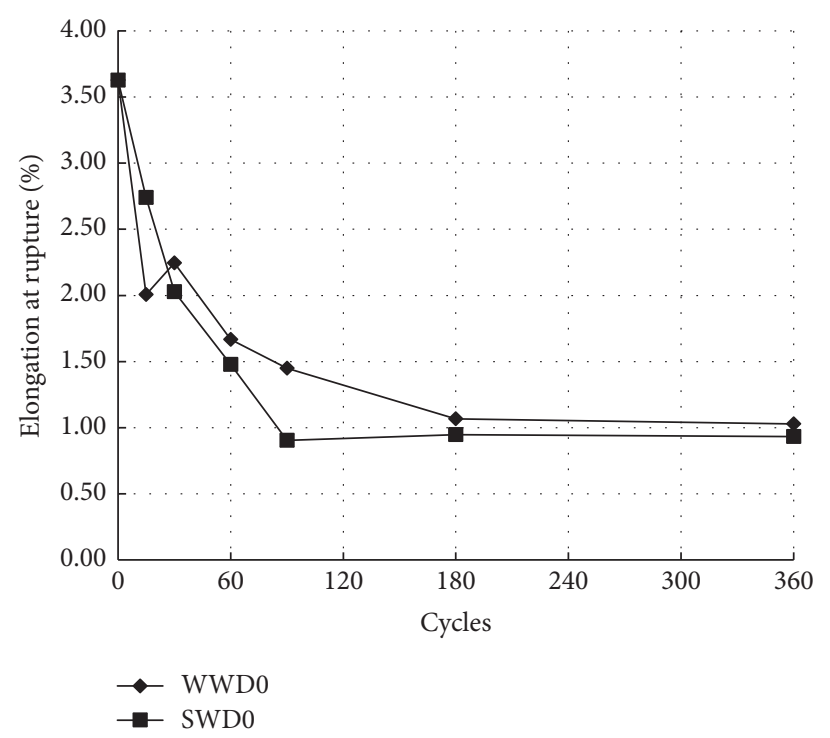

(c)

Figure 3: Mechanical properties of unstressed specimens exposed to WD cycles: (a) tensile strength; (b) elastic modulus; (c) elongation at rupture. Note. WWD0 is unstressed specimen exposed to WD cycles of distilled water; and SWD0 is unstressed specimen exposed to WD cycles of saltwater.

cycles. The reduction in the tensile strength, modulus, and elongation at rupture of aged specimens versus the number of cycles is presented in Figure 3. Both the tensile strength and elastic modulus have an initial increase after $15 \mathrm{WD}$ cycles, followed by a continued decline with the increasing number of cycles. Although the specimens were cured at room temperature for 3 days and then cured in an oven at $60^{\circ} \mathrm{C}$ for 3 hours, the resin was not polymerized completely. Immersion in water led to the occurrence of postcuring of polymer, yielding an initial increase in tensile strength and modulus $[24,26,27]$. The differential scanning calorimetry (DSC) measurement of the identical samples confirmed that the resin partially cured before conditions [24].

Further exposure to WD cycles led to a steady decrease in tensile strength and modulus. After 360 cycles, the loss of tensile strength is $9 \%$ and $12 \%$ for WWD0 and SWD0, respectively, and the loss of modulus is $16 \%$ and $12 \%$ for WWD0 and SWD0, respectively, as shown in Figures 3(a) and 3 (b). However, the elongation at rupture decreased initially after 90 cycles and almost remained unchanged from 90 cycles to 360 cycles. After 360 cycles, the loss of elongation at rupture is $72 \%$ and $74 \%$ for WWD0 and SWD0, respectively. The durability of unstressed specimens under WD cycles of distilled water has negligible differences with that of specimens under WD cycles of saltwater. The sharp decrease of elongation at rupture indicates that GFRP composites become brittle in exposure of WD cycles.

Micro observations were conducted to examine the physical damage of GFRP composites due to exposure to WD cycles. Figure 4 shows the typical micrographs of the 


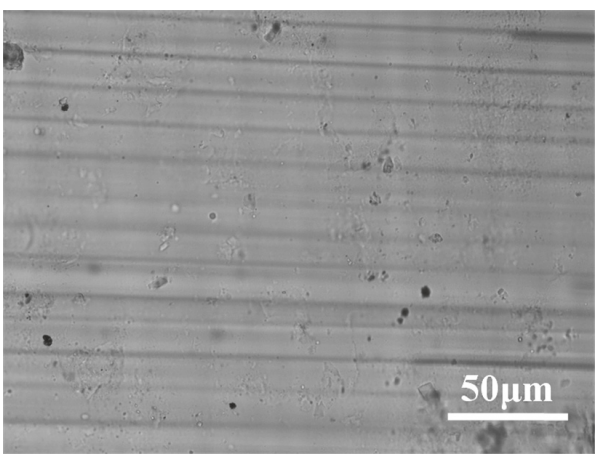

(a)

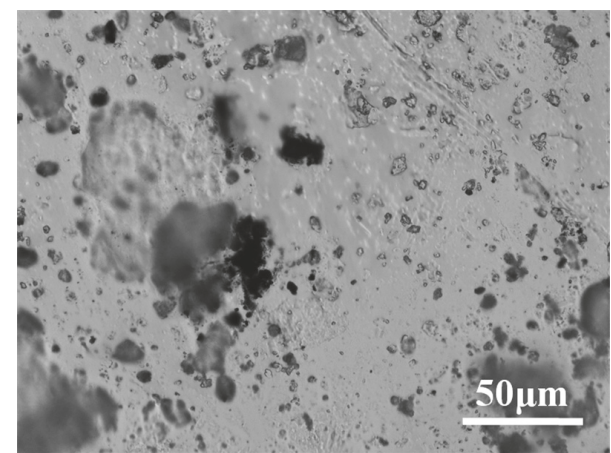

(b)

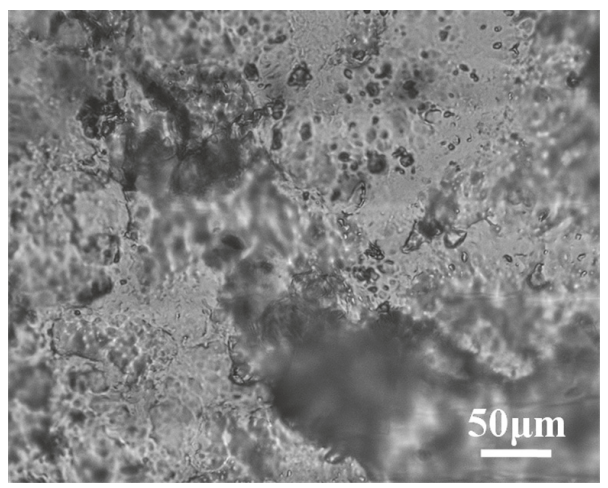

(c)

FIGURE 4: Micrographs of the surfaces $(\times 50)$ of the unstressed specimens: (a) unconditioned specimen; (b) SWD0 after 60 WD cycles; and (c) WWD0 after $180 \mathrm{WD}$ cycles.

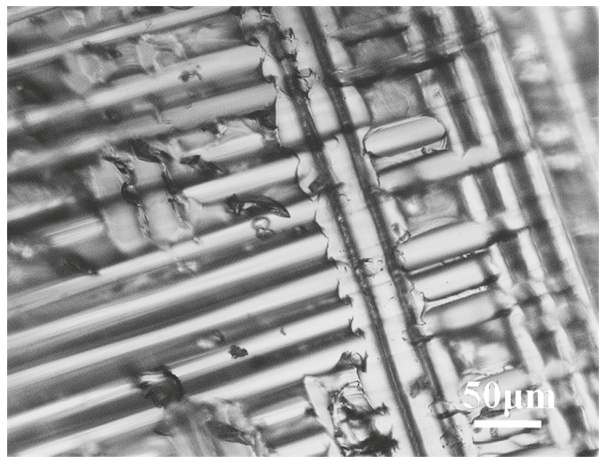

(a)

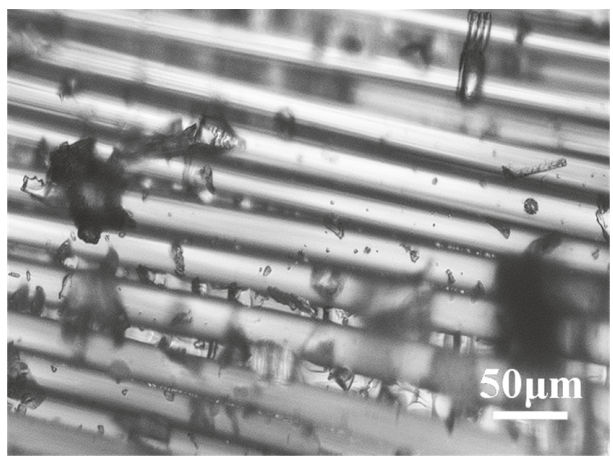

(c)

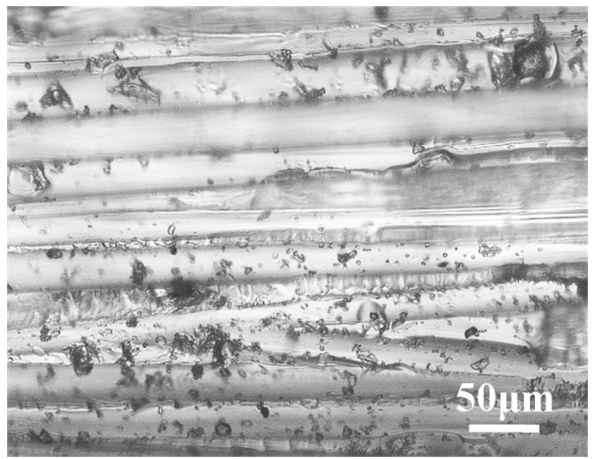

(b)

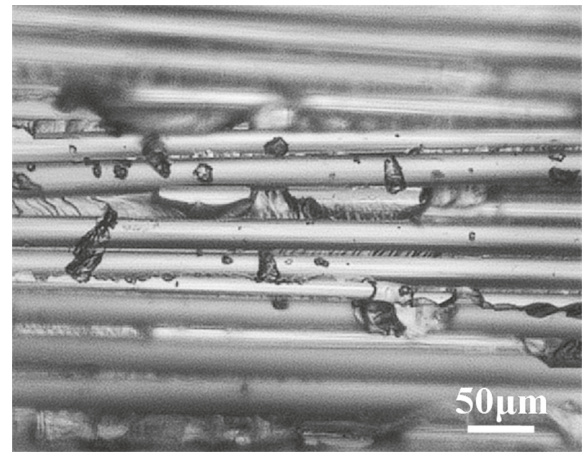

(d)

FIGURE 5: Micrographs of the longitudinal section $(\times 50)$ of the unstressed specimens: (a) unconditioned specimen; (b) WWD0 after 60 WD cycles; (c) SWD0 after 60 WD cycles; and (d) WWD0 after 180 WD cycles. 
TABLE 2: Mechanical properties of GFRP under the combined effects of sustained loads and WD cycles.

\begin{tabular}{|c|c|c|c|c|c|}
\hline Specimens & Load level & WD cycles & $\begin{array}{l}\text { Tensile strength } \\
(\mathrm{MPa})\end{array}$ & $\begin{array}{l}\text { Elastic modulus } \\
\quad(\mathrm{GPa})\end{array}$ & $\begin{array}{c}\text { Elongation } \\
(\mathrm{mm})\end{array}$ \\
\hline \multirow{7}{*}{ WWD2 } & \multirow{7}{*}{$20 \%$} & 0 & 416.75 & 24.70 & 1.813 \\
\hline & & 15 & 440.85 & 26.87 & 0.958 \\
\hline & & 30 & 487.13 & 27.17 & 1.235 \\
\hline & & 60 & 508.28 & 28.10 & 0.929 \\
\hline & & 90 & 431.74 & 24.56 & 0.684 \\
\hline & & 180 & 403.64 & 22.65 & 0.507 \\
\hline & & 360 & 345.90 & 20.61 & 0.484 \\
\hline \multirow{7}{*}{ WWD4 } & \multirow{7}{*}{$40 \%$} & 0 & 416.75 & 24.70 & 1.813 \\
\hline & & 15 & 435.91 & 25.89 & 1.258 \\
\hline & & 30 & 474.93 & 28.27 & 1.017 \\
\hline & & 60 & 532.71 & 29.75 & 0.873 \\
\hline & & 90 & 442.15 & 24.00 & 0.557 \\
\hline & & 180 & 390.90 & 22.05 & 0.485 \\
\hline & & 360 & 329.12 & 19.59 & 0.443 \\
\hline \multirow{7}{*}{ SWD2 } & \multirow{7}{*}{$20 \%$} & 0 & 416.75 & 24.70 & 1.813 \\
\hline & & 15 & 470.66 & 24.29 & 0.703 \\
\hline & & 30 & 478.37 & 25.10 & 1.055 \\
\hline & & 60 & 499.34 & 27.36 & 0.980 \\
\hline & & 90 & 477.48 & 26.85 & 0.796 \\
\hline & & 180 & 398.63 & 22.28 & 0.505 \\
\hline & & 360 & 347.23 & 19.89 & 0.486 \\
\hline \multirow{7}{*}{ SWD4 } & \multirow{7}{*}{$40 \%$} & 0 & 416.75 & 24.70 & 1.813 \\
\hline & & 15 & 478.71 & 25.87 & 0.942 \\
\hline & & 30 & 493.56 & 27.87 & 1.071 \\
\hline & & 60 & 534.80 & 28.56 & 0.971 \\
\hline & & 90 & 465.53 & 25.35 & 0.654 \\
\hline & & 180 & 390.89 & 21.98 & 0.431 \\
\hline & & 360 & 328.69 & 18.90 & 0.423 \\
\hline
\end{tabular}

surfaces of unconditioned and conditioned specimens. It is observed that the void content of the polyester resin increases gradually with the number of WD cycles in both distilled water and saltwater. Voids and porosities not only lead to water diffusion but also lead to stress concentration. Once water molecules diffuse into a polyester matrix, they would make hydrogen-bond with the cross-linked polymer at the polar ester linkages [28]. As shown in Figure 5, hydrolysis of isophthalic polyester resins occurred due to exposure to WD cycles. Moisture absorption test of the identical samples showed that the moisture uptake content $M_{t}$ decreased with the immersion time after $M_{t}$ reached its peak value, which confirmed the hydrolysis of isophthalic polyester resins [24]. Moreover, chemical reaction between glass fibers and water usually cause alkali elements to leach out [29]. In addition, for specimens exposed to WD cycles of saltwater, the spatial distribution of $\mathrm{Cl}$ from $\mathrm{NaCl}$ correlates with that of $\mathrm{Si}$ from the E-glass fibers, yielding the aggravation of deterioration in tensile property of GFRP composites.

3.2. Specimens with Sustained Loads. Table 2 shows the mechanical properties of GFRP under combined effects of 


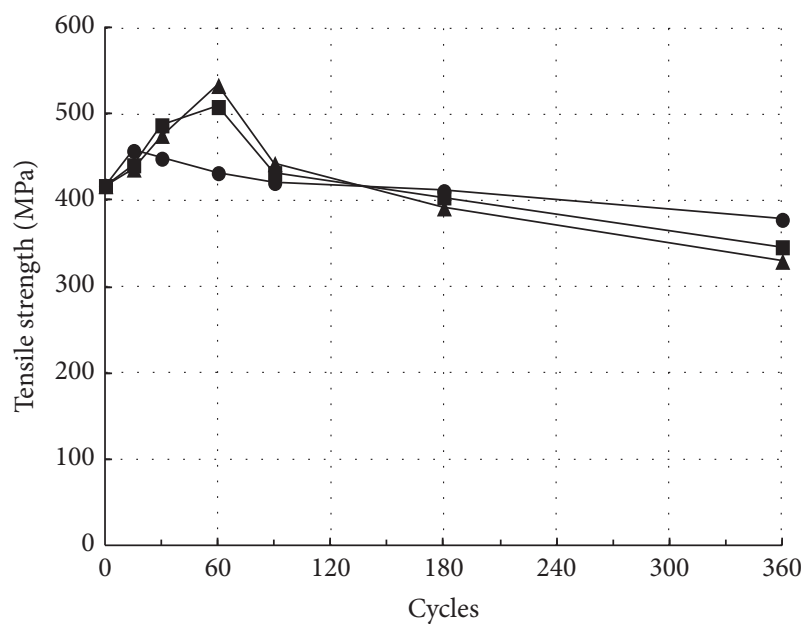

- WWD0

$\rightarrow$ WWD2

$\leftarrow$ WWD4

(a)

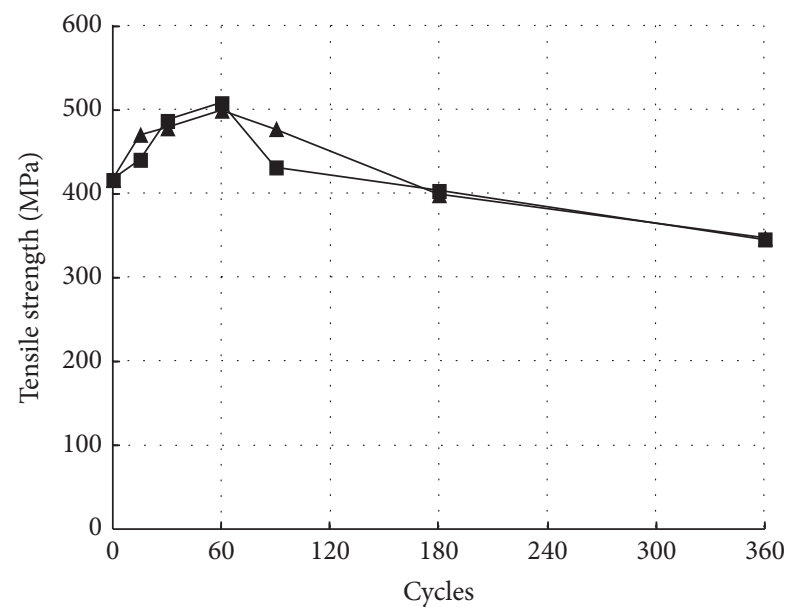

$\rightarrow$ WWD2

SWD2

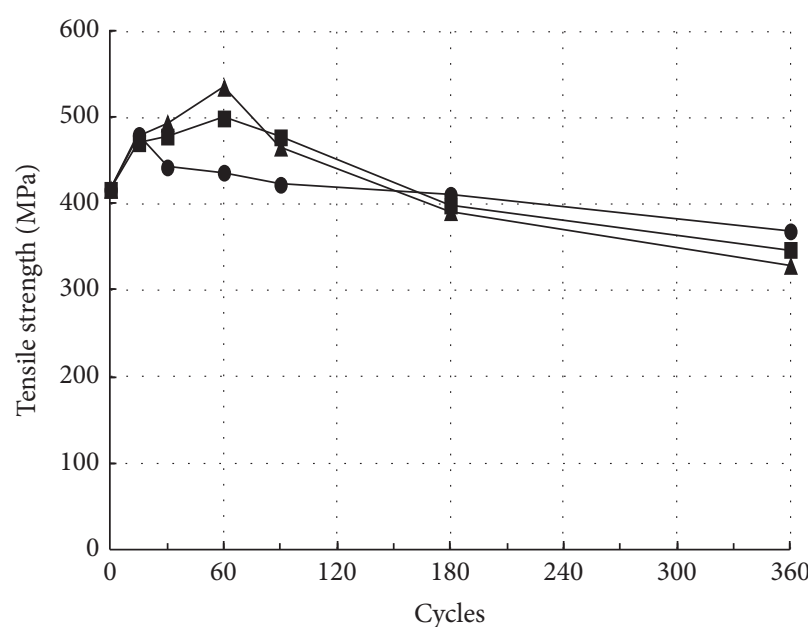

- SWD0

- SWD2

$\leftarrow$ SWD4

(b)

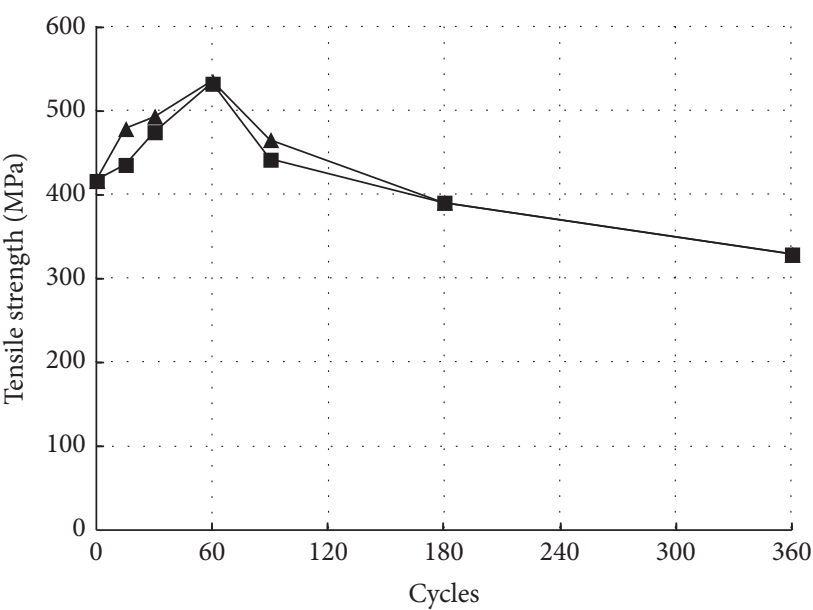

WWD4

SWD4

(d)

FIGURE 6: Tensile strength of stressed specimens (a) subjected to WD cycles of distilled water and different loads; (b) subjected to WD cycles of saltwater and different loads; (c) subjected to WD cycles and 20\% ultimate tensile strength; (d) subjected to WD cycles and 40\% ultimate tensile strength. Note. WWD2 and WWD4 are specimens exposed to WD cycles of distilled water and subjected to $20 \%$ and $40 \%$ ultimate tensile strength, respectively, and SWD2 and SWD4 are specimens exposed to WD cycles of saltwater and subjected to $20 \%$ and $40 \%$ ultimate tensile strength, respectively.

sustained loads and WD cycles. The specimens with sustained loads have an initial increase in both tensile strength and elastic modulus after 60 cycles, as shown in Figures 6 and 7. After 60 cycles, the tensile strength increased by $22 \%$, $20 \%, 28 \%$, and $28 \%$ for WWD2, SWD2, WWD4, and SWD4, respectively. Meanwhile, after 60 cycles, the elastic modulus increased by $14 \%, 11 \%, 20 \%$, and $16 \%$, for WWD2, SWD2, WWD4, and SWD4, respectively. These results indicate that the initial increases of tensile strength and elastic modulus of the specimens with sustained loads are greater than those of specimens without sustained loads, which may be attributed to the combined effects of postcuring of resin and the sustained tensile stress. Similar behavior was also observed by Abdel-Magid et al. [30]. The tensile stress aligns the fibers in the stress direction and endows the material with more efficiency in carrying the load after short period of prestress.

From 60 cycles to 360 cycles, the tensile strength and elastic modulus of stressed specimens decreased steadily. After 360 cycles, the tensile strength decreased by $17 \%, 17 \%$, $21 \%$, and $21 \%$ for WWD2, SWD2, WWD4, and SWD4, 


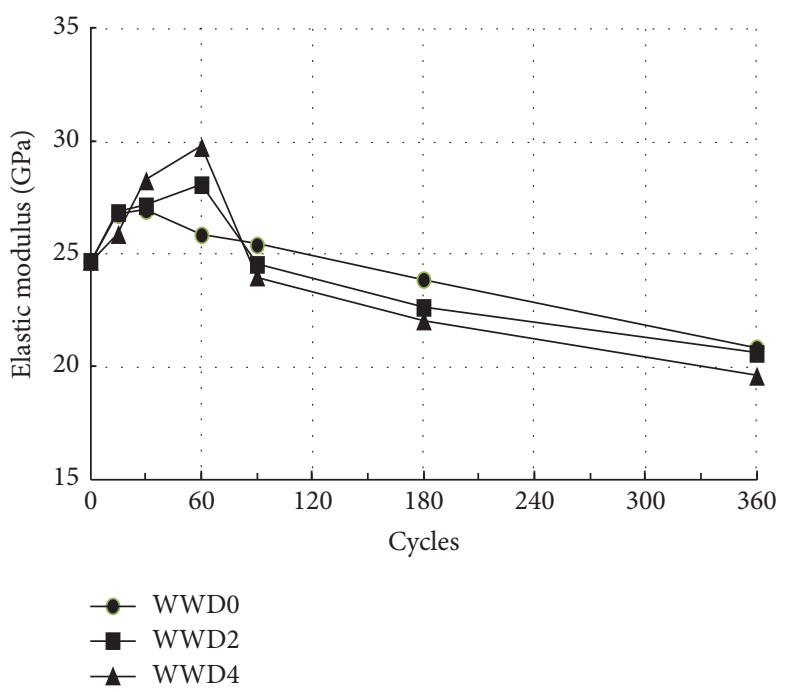

(a)

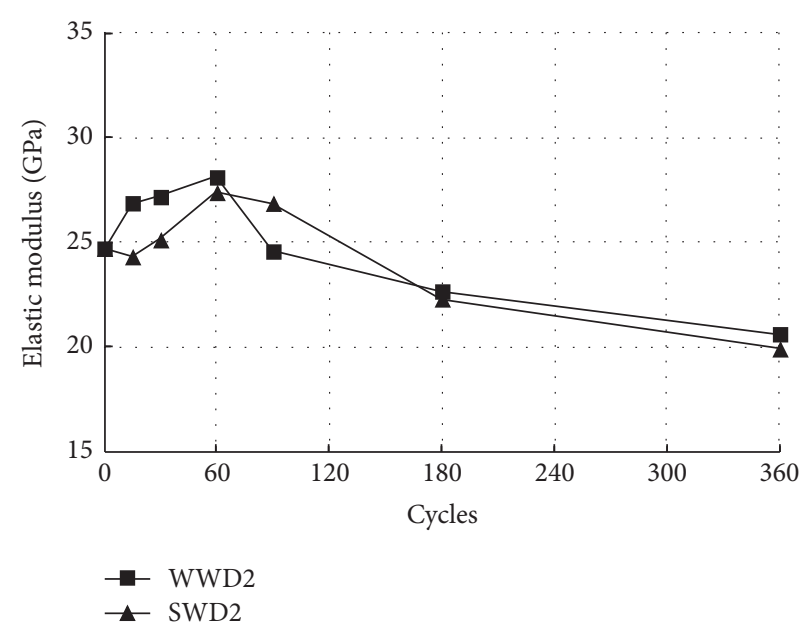

(c)

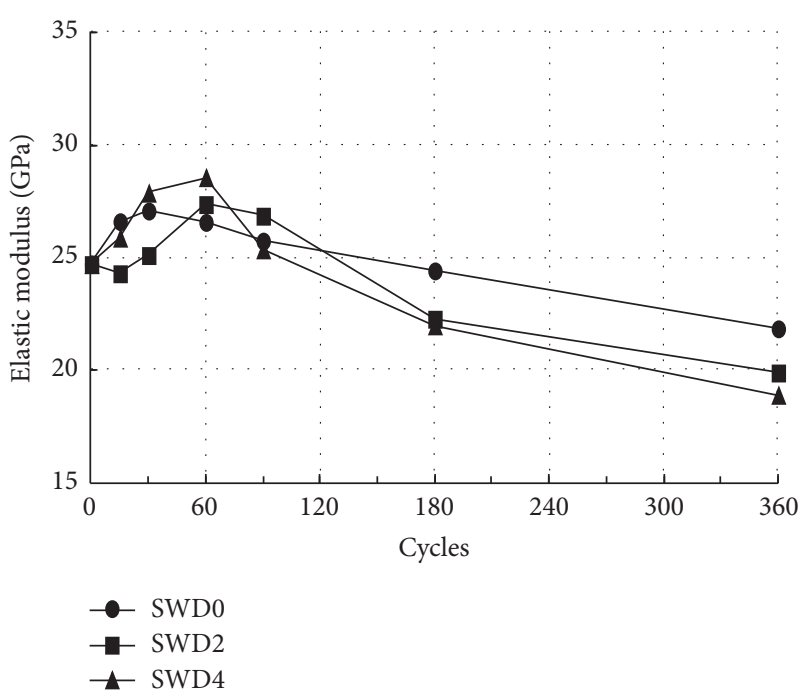

(b)

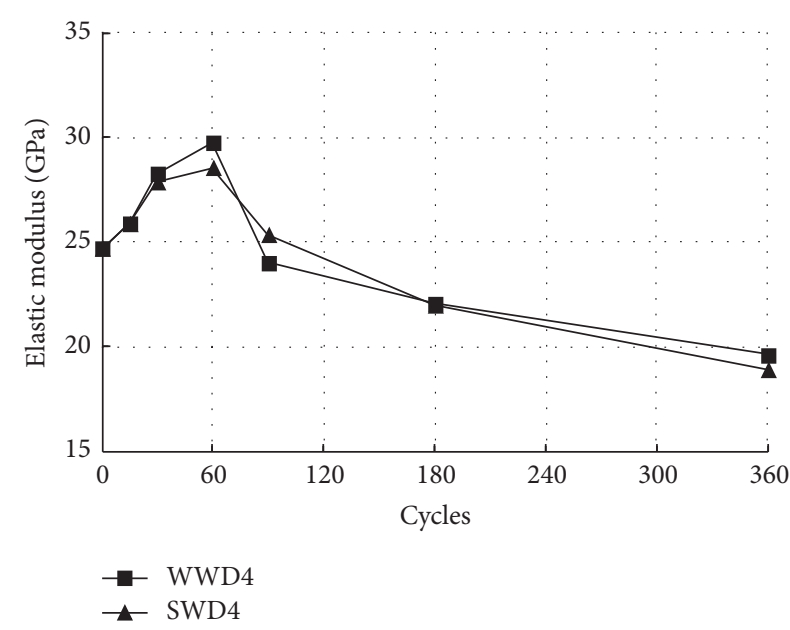

(d)

FIGURE 7: Elastic modulus of stressed specimens (a) subjected to WD cycles of distilled water and different loads; (b) subjected to WD cycles of saltwater and different loads; (c) subjected to WD cycles and 20\% ultimate tensile strength; (d) subjected to WD cycles and 40\% ultimate tensile strength.

respectively, and the elastic modulus decreased by $17 \%$, $19 \%, 21 \%$, and $23 \%$ for WWD2, SWD2, WWD4, and SWD4, respectively. Meanwhile, after 360 cycles, the loss of elongation at rupture is $73 \%, 73 \%, 76 \%$, and $77 \%$ for WWD2, SWD2, WWD4, and SWD4, respectively, as shown in Figure 8. It is obvious that the increase of sustained loads leads to a decrease in tensile property. Moreover, the effect of WD cycles of saltwater on elastic modulus and elongation at rupture is greater than that of WD cycles of distilled water. Both water diffusion and stress corrosion are associated with the degradation of resin and the interface between fiber and matrix. The previous research of authors has proven that the effect of saltwater immersion on tensile property is greater than that of tap water due to the chemical reaction between leaked $\mathrm{Cl}$ ions from saltwater and metal ions ( $\mathrm{Si}, \mathrm{Na}$, and $\mathrm{K}$ ) from E-glass fibers [24].

The micrographs of the surfaces of stressed specimens showed that the voids of polyester resins progressed in both distilled water and saltwater, as shown in Figure 9. Hydrolysis of isophthalic polyester resins was also observed under the combined effects of WD cycles and sustained loads, as shown in Figure 10.

\section{Prediction of Long-Term Behavior}

Several models have been developed to predict the longterm responses of FRP composites based on Arrhenius concept which assumed that the single dominant deterioration 

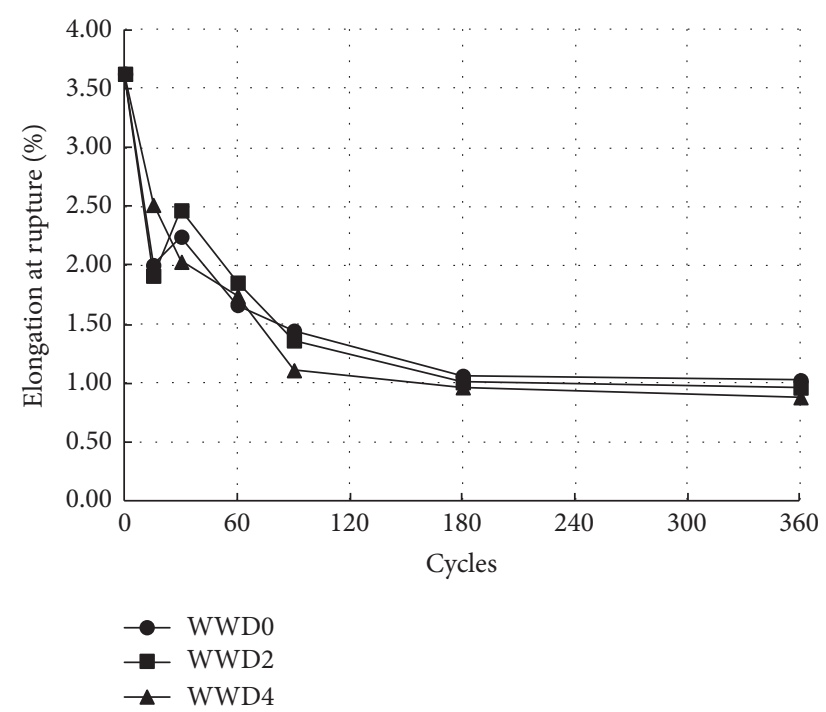

(a)

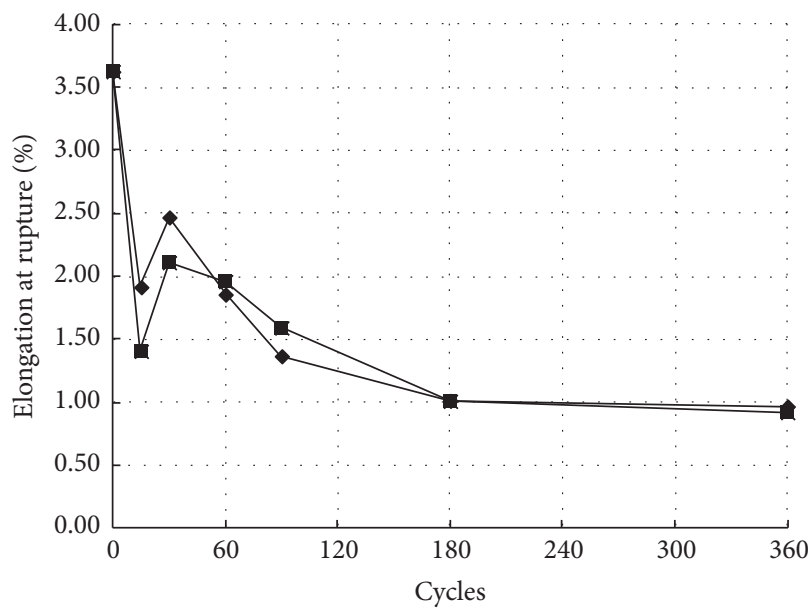

WWD2

SWD2

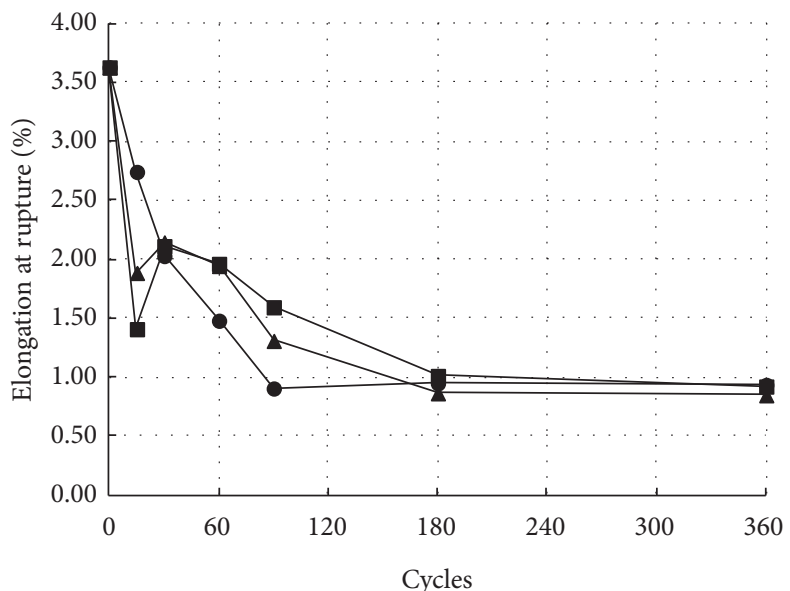

- SWD0

$\rightarrow$ SWD2

(b)

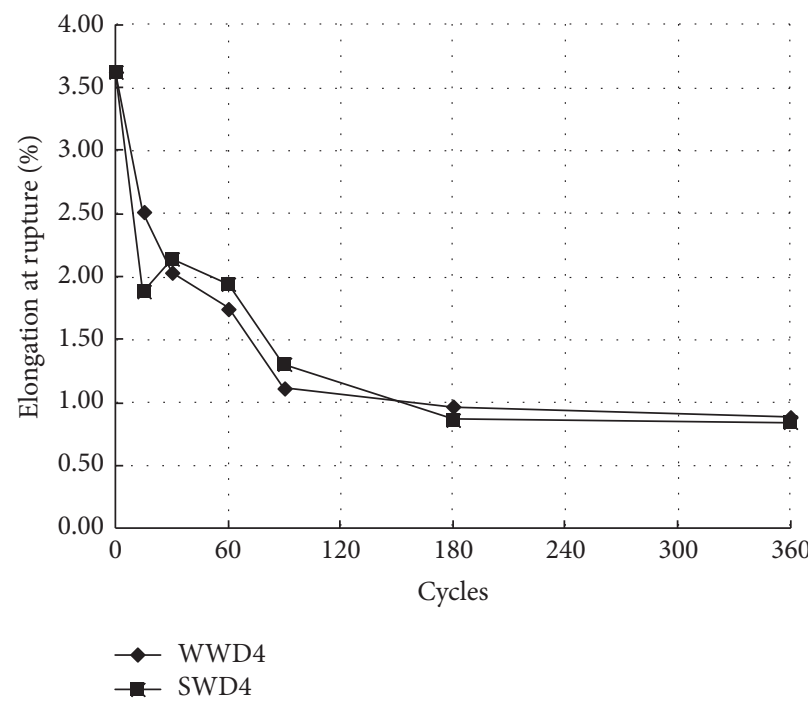

(d)

(c)

FIGURE 8: Elongation at rupture of stressed specimens (a) subjected to WD cycles of distilled water and different loads; (b) subjected to WD cycles of saltwater and different loads; (c) subjected to WD cycles and 20\% ultimate tensile strength; (d) subjected to WD cycles and 40\% ultimate tensile strength.

mechanism of the material will not change with time and temperature in corrosive environment $[8,31]$.

The Arrhenius equation for predicting the mechanical property of FRP composites is given by [8]

$$
P(t)=\frac{P_{0}}{100}[A \ln (t)+B]
$$

where $P(t)$ and $P_{0}$ are the performance attributes of FRP composites at exposure time $t$ and zero time of exposure, respectively, $A$ is degradation rate, and $B$ is a material constant associated with postcure progression of polymer during exposure. A value of $B>100$ relates to the initial dominance of postcure processes in environmental exposure, while a value of $B=100$ indicates full polymerization of the resin. Equation (1) is only valid for $t>0$. In the case of $t=0$, the percent retention of $P(t)$ is assumed to be $100 \%$.

For exposure in WD cycles, (1) can be transformed into

$$
P(x)=\frac{P_{0}}{100}[A \ln (x)+B]
$$

where $x$ is the number of WD cycles.

The tensile strength and elastic modulus of FRP composites tend to increase gradually with time in the initial postcuring processes and then become stable, regardless of 


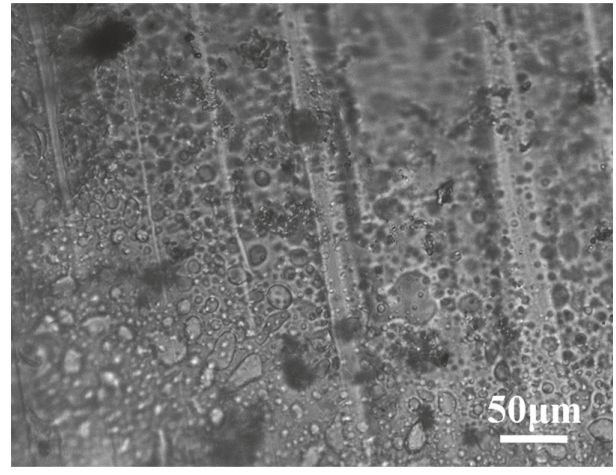

(a)

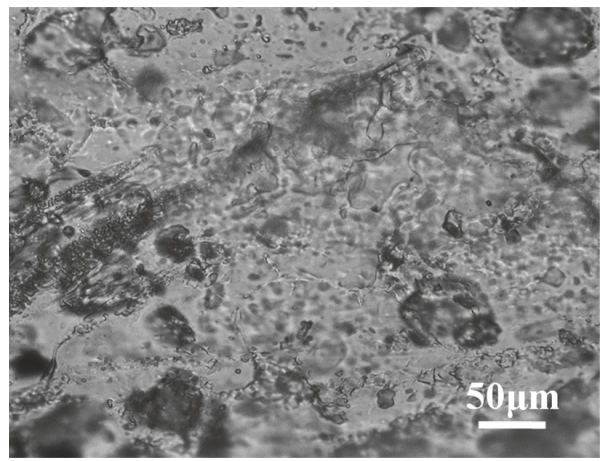

(c)

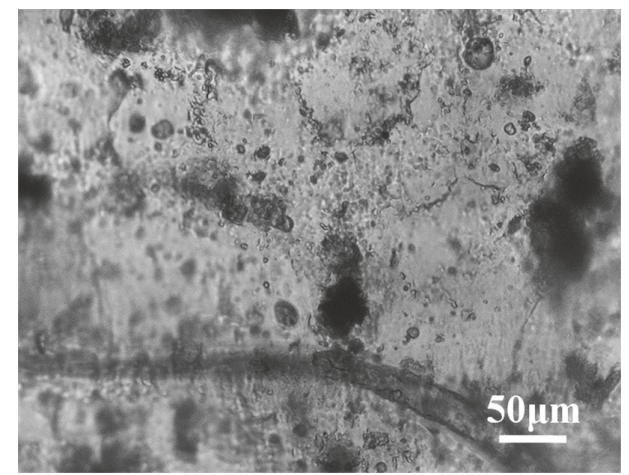

(b)

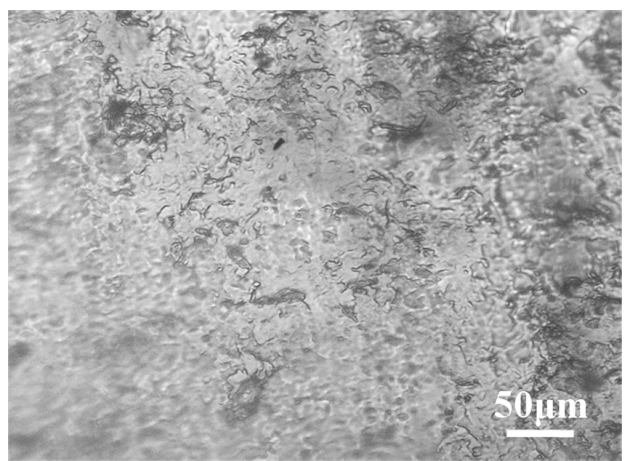

(d)

FIGURE 9: Micrographs of the surfaces (×50) of stressed specimens: (a) SWD2 after 60 WD cycles; (b) SWD2 after 180 WD cycles; (c) WWD2 after 180 WD cycles; and (d) SWD4 after 180 WD cycles.

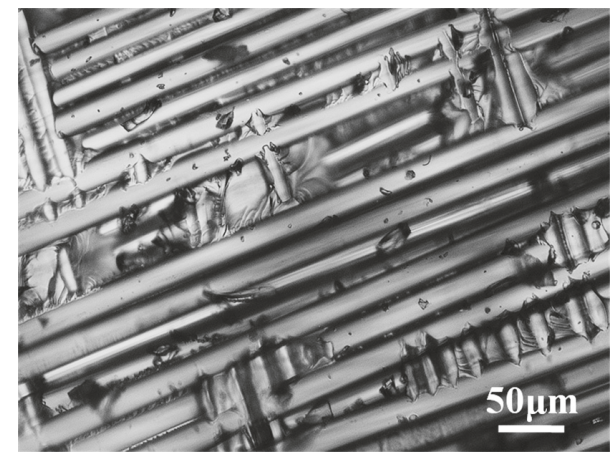

(a)

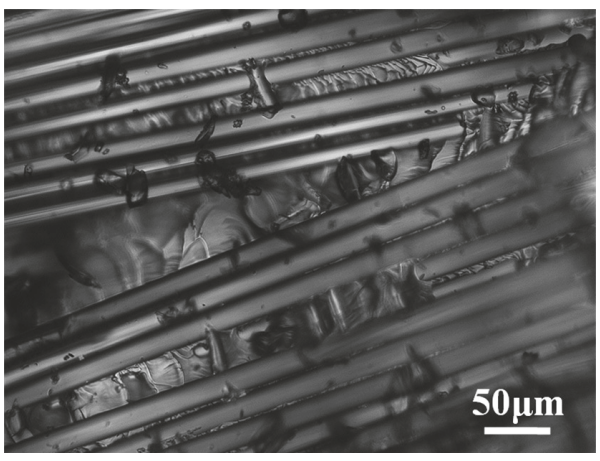

(c)

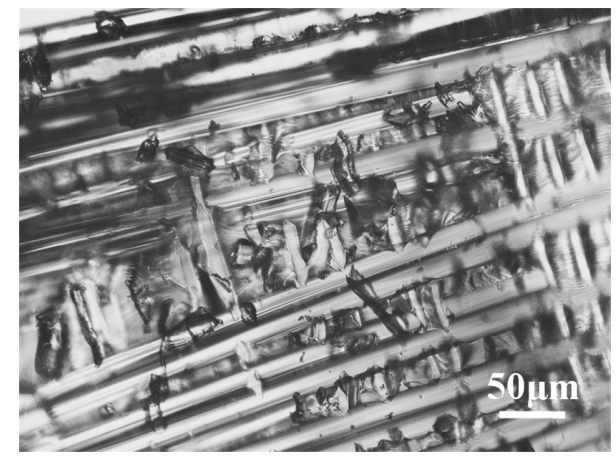

(b)

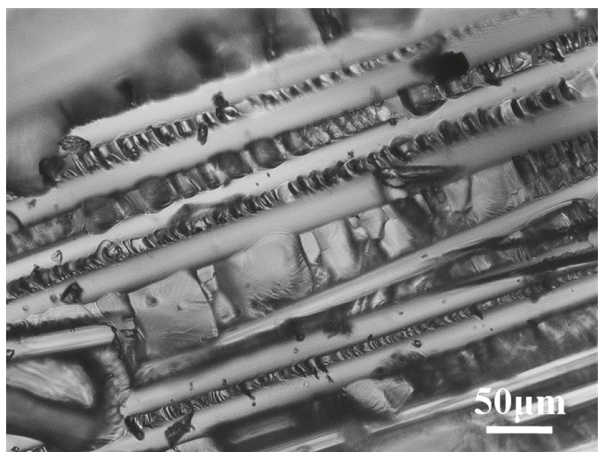

(d)

FIGURE 10: Micrographs of the longitudinal section (×50) of stressed specimens: (a) SWD2 after 60 WD cycles; (b) SWD2 after 180 WD cycles; (c) WWD2 after 180 WD cycles; and (d) WWD4 after 180 WD cycles. 


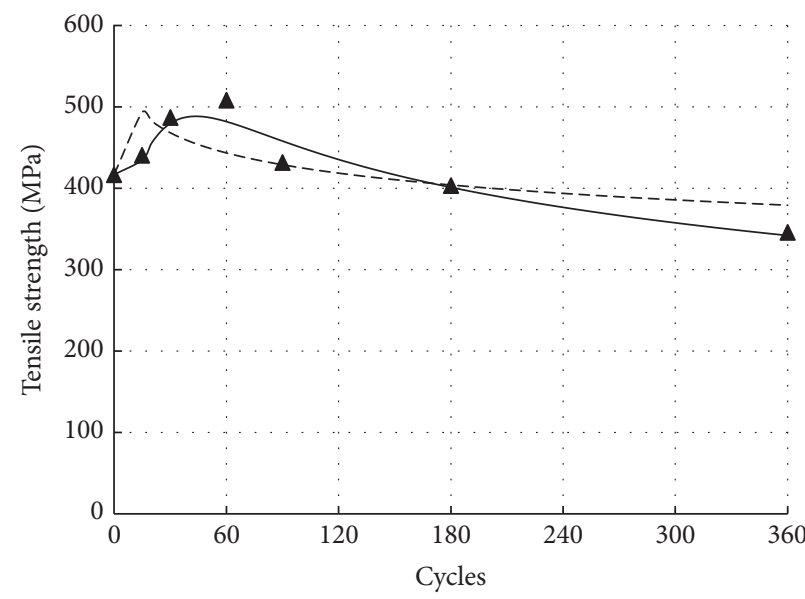

\ Experimental data

--- Eq. (2)

- Eq. (5)

(a) WWD2

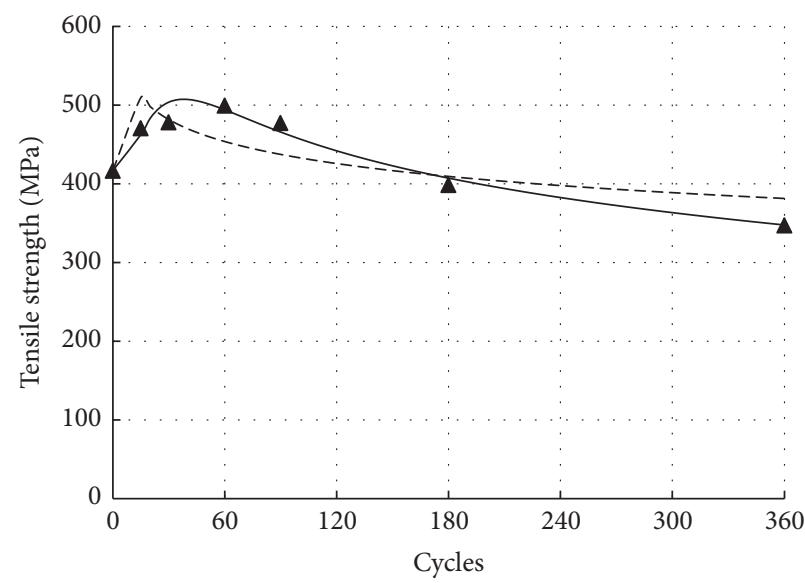

$\Delta$ Experimental data

- Eq. (2)

- Eq. (5)

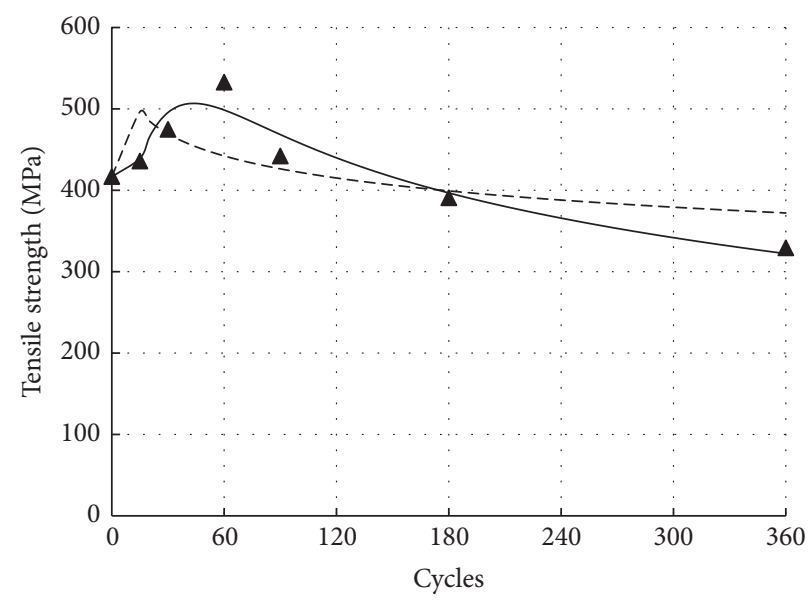

\ Experimental data

--- Eq. (2)

- Eq. (5)

(b) WWD4

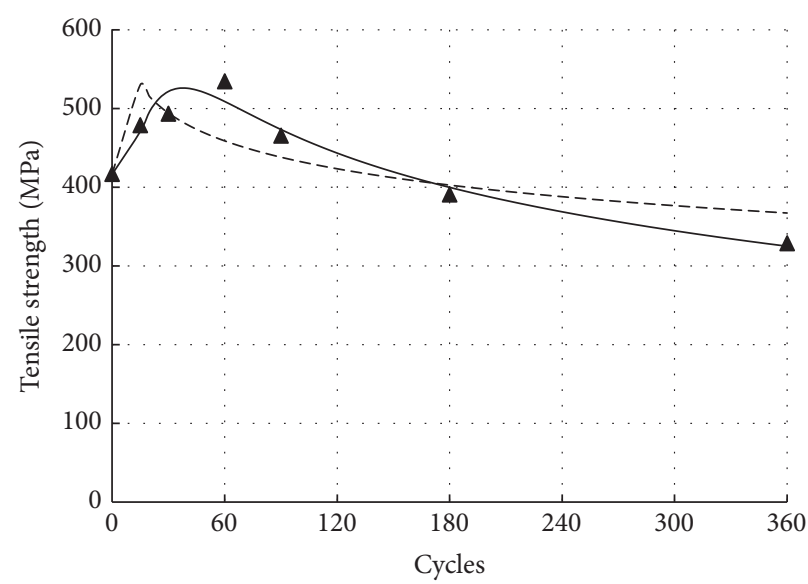

- Experimental data

-- Eq. (2)

- Eq. (5)

(c) SWD2

(d) SWD4

FIGURE 11: Comparison of prediction of tensile strength.

the effects of environmental attacks. Thus, the effects of postcuring on the mechanical property of FRP composites can be described as a two-parameter exponential equation:

$$
f(t)=\alpha\left(1-\beta^{-t}\right),
$$

where $f(t)$ is the performance attribute of FRP composites due to postcuring, and $\alpha$ and $\beta$ are regression constants.

Considering the combined effects of postcure processes and exposure environments, the prediction model can be given by

$$
P(t)=\frac{P_{0}}{100}[A \ln (t)+100]+\alpha\left(1-\beta^{-t}\right) .
$$

For exposure in WD cycles, (3) can be transformed into

$$
P(x)=\frac{P_{0}}{100}[A \ln (x)+100]+\alpha\left(1-\beta^{-x}\right),
$$

where $x$ is the number of WD cycles.

The predictive equations of tensile strength and elastic modulus according to (5) and (2) are given in Tables 3 and 4, respectively. For unstressed specimens, the predicted results from (2) and (5) agree well with those obtained from experiments. However, for specimens with sustained loads, (5) provides more accurate prediction results than (2), as shown in Figures 11 and 12. 


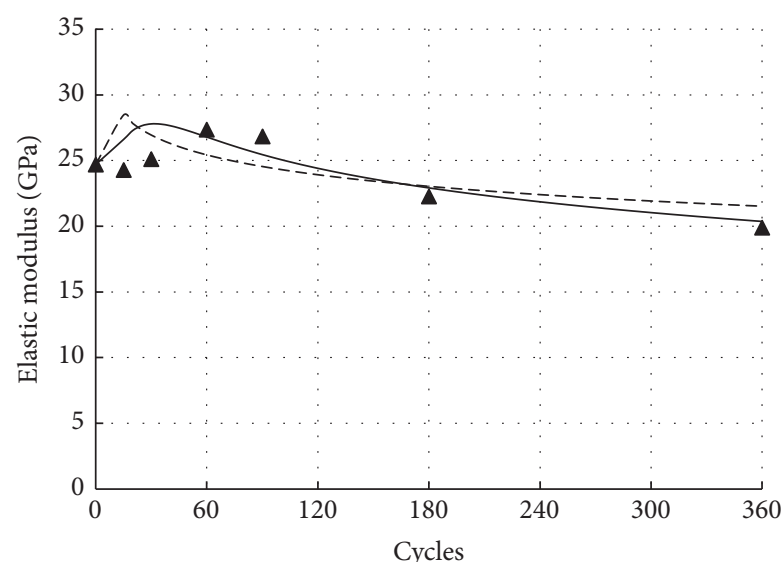

- Experimental data

--- Eq. (2)

- Eq. (5)

(a) WWD2

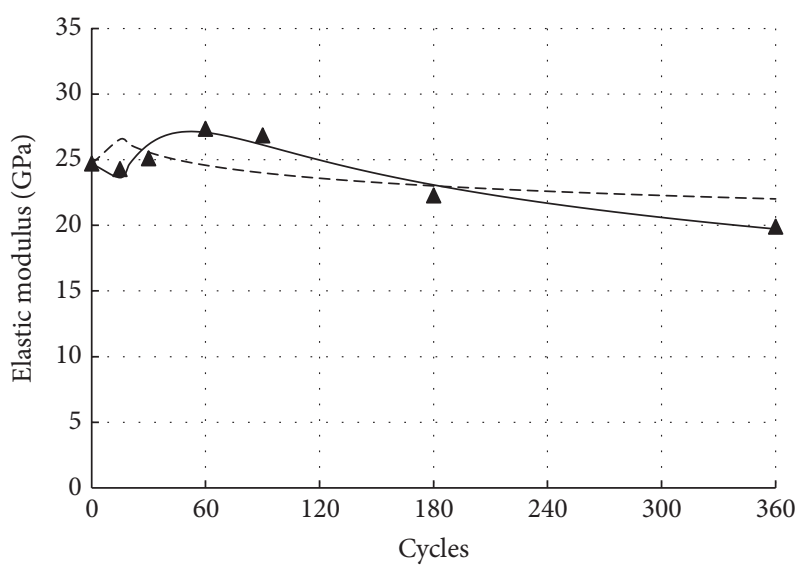

\ Experimental data

--- Eq. (2)

- Eq. (5)

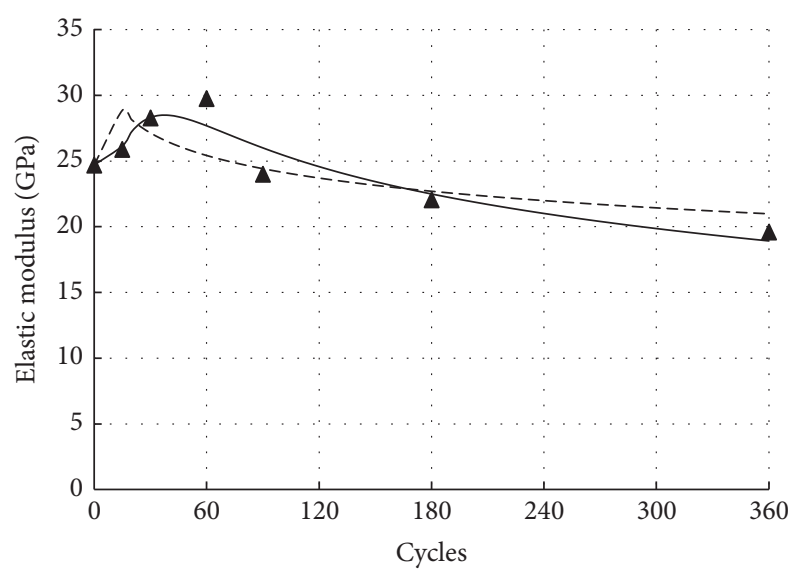

$\Delta$ Experimental data

--- Eq. (2)

- Eq. (5)

(b) WWD4

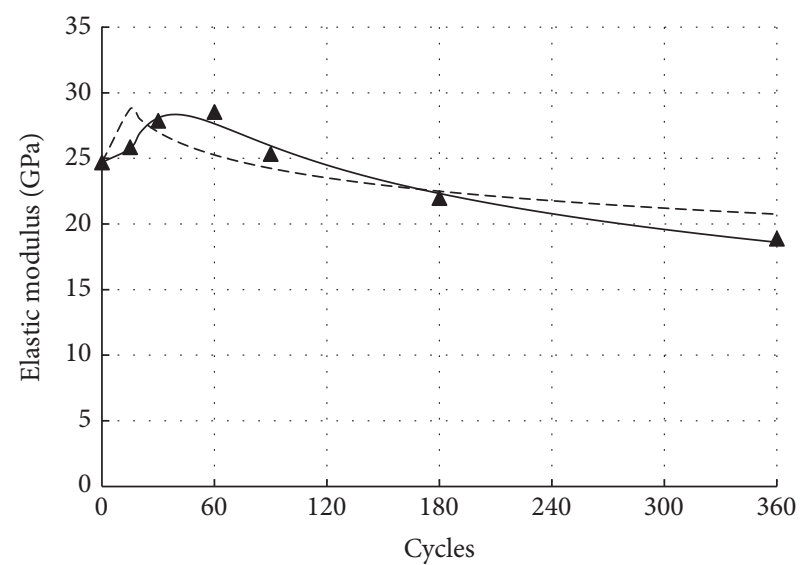

$\Delta$ Experimental data

--- Eq. (2)

- Eq. (5)

(c) SWD2

(d) SWD4

FIGURE 12: Comparison of prediction of elastic modulus.

\section{Conclusions}

The durability of GFRP composites exposed to WD cycles of both distilled water and saltwater was investigated under three different sustained loading levels. The tensile properties of both the unconditioned and conditioned specimens were tested to study the long-term behavior of GFRP composites under different WD cycles. Based on Arrhenius concept, a model was developed to predict the tensile property of GFRP. In addition, the electron microscopy (EM) was used to characterize the aging effect on GFRP composites. The results obtained from this study are summarized as follows:

(1) The tensile strength and elastic modulus of all conditioned specimens increased initially and then decreased with the increase of exposure cycle numbers. The coupled effects of postcuring and alignment of the fibers in the stress direction yield greater increases in tensile strength and elastic modulus of stressed specimens than those of unstressed specimens. Further exposure to WD cycles led to a steady decrease in tensile strength and modulus. For unstressed specimens, the degradation of the tensile property of specimens exposed to distilled water was almost equal to specimens exposed to saltwater after 360 cycles. However, for stressed specimens, the effect of WD cycles of saltwater on elastic modulus and elongation at rupture is greater than that of WD cycles of distilled water. Moreover, increasing sustained loads led to a decrease in tensile property.

(2) The elongation at rupture decreased sharply with the increasing number of cycles in both distilled water 
TABLE 3: Predictive equations for tensile strength.

\begin{tabular}{lccc}
\hline Exposure environment & Load level & Equation & $R$-square \\
\hline & $0 \%$ & $4.1675[-6.614 \ln (x)+100]+128.63\left(1-1.16^{-x}\right)$ & 0.97 \\
& & $4.1675[-5.794 \ln (x)+126.74]$ & 0.99 \\
Wet-dry cycles in distilled water & $20 \%$ & $4.1675[-20.479 \ln (x)+100]+427.57\left(1-1.06^{-x}\right)$ & 0.92 \\
& $40 \%$ & $4.1675[-8.590 \ln (x)+141.59]$ & 0.51 \\
& & $4.1675[-25.814 \ln (x)+100]+538.77\left(1-1.06^{-x}\right)$ & 0.91 \\
Wet-dry cycles in saltwater & $0 \%$ & $4.1675[-9.379 \ln (x)+144.51]$ & 0.42 \\
\hline & $20 \%$ & $4.1675[-4.912 \ln (x)+100]+103.00\left(1-1.21^{-x}\right)$ & 0.94 \\
& & $4.1675[-7.430 \ln (x)+134.38]$ & 0.96 \\
& $40 \%$ & $4.1675[-20.604 \ln (x)+100]+436.32\left(1-1.07^{-x}\right)$ & 0.95 \\
\hline
\end{tabular}

Note. $R$-square is the coefficient of determination. It denotes the proportion of the variance in the dependent variable which is predictable from the independent variables.

TABLE 4: Predictive equations for elastic modulus.

\begin{tabular}{|c|c|c|c|}
\hline Exposure environment & Load level & Equation & $R$-square \\
\hline \multirow{6}{*}{ Wet-dry cycles in distilled water } & \multirow{2}{*}{$0 \%$} & $0.247[-11.092 \ln (x)+100]+12.77\left(1-1.091^{-x}\right)$ & 0.97 \\
\hline & & $0.247[-7.347 \ln (x)+132.63]$ & 0.84 \\
\hline & \multirow{2}{*}{$20 \%$} & $0.247[-14.902 \ln (x)+100]+17.33\left(1-1.08^{-x}\right)$ & 0.93 \\
\hline & & $0.247[-8.835 \ln (x)+139.158]$ & 0.75 \\
\hline & \multirow{2}{*}{$40 \%$} & $0.247[-20.873 \ln (x)+100]+24.57\left(1-1.068^{-x}\right)$ & 0.88 \\
\hline & & $0.247[-10.062 \ln (x)+144.14]$ & 0.57 \\
\hline \multirow{6}{*}{ Wet-dry cycles in saltwater } & \multirow{2}{*}{$0 \%$} & $0.247[-10.324 \ln (x)+100]+12.49\left(1-1.08^{-x}\right)$ & 0.98 \\
\hline & & $0.247[-6.07 \ln (x)+128.83]$ & 0.78 \\
\hline & \multirow{2}{*}{$20 \%$} & $0.247[-19.638 \ln (x)+100]+23.57\left(1-1.049^{-x}\right)$ & 0.85 \\
\hline & & $0.247[-5.789 \ln (x)+123.24]$ & 0.34 \\
\hline & \multirow{2}{*}{$40 \%$} & $0.247[-21.73 \ln (x)+100]+25.5\left(1-1.065^{-x}\right)$ & 0.98 \\
\hline & & $0.247[-10.22 \ln (x)+144.13]$ & 0.63 \\
\hline
\end{tabular}

and saltwater, which indicated the GFRP composites became brittle in exposure of WD cycles. The sustained loads have insignificant influences on the elongation at rupture.

(3) A modified model which considered the effects of postcure processes was developed to predict the tensile strength and elastic modulus of GFRP composites subjected to WD cycles. It is shown that the model can capture the degradation trend of specimens under the combined effects of WD cycles and sustained loads.

\section{Conflicts of Interest}

The authors declare that they have no conflicts of interest.

\section{Acknowledgments}

The financial support from the National Natural Science Foundation of China (Grant 51578283), Jiangsu Province Science and Technology Support Program of Construction Industry Modernization (Grant 2017-13), and Key Program of the National Natural Science Foundation of China (Grant 51238003) is greatly appreciated.

\section{References}

[1] C. Tuakta and O. Büyüköztürk, "Conceptual model for prediction of FRP-concrete bond strength under moisture cycles," Journal of Composites for Construction, vol. 15, no. 5, pp. 743756, 2011.

[2] K. Soudki, E. El-Salakawy, and B. Craig, "Behavior of CFRP strengthened reinforced concrete beams in corrosive environment," Journal of Composites for Construction, vol. 11, no. 3, pp. 291-298, 2007.

[3] A. Belarbi and S.-W. Bae, "An experimental study on the effect of environmental exposures and corrosion on RC columns with FRP composite jackets," Composites Part B: Engineering, vol. 38, no. 5-6, pp. 674-684, 2007.

[4] H. A. Toutanji and T. El-Korchi, "Tensile durability of cementbased frp composite wrapped specimens," Journal of Composites for Construction, vol. 3, no. 1, pp. 38-45, 1999.

[5] S.-P. Yin, C. Peng, and Z.-Y. Jin, "Research on Mechanical Properties of Axial-Compressive Concrete Columns Strengthened 
with TRC under a Conventional and Chloride Wet-Dry Cycle Environment," Journal of Composites for Construction, vol. 21, no. 1, Article ID 04016061, 2017.

[6] V. M. Karbhari and M. A. Abanilla, "Design factors, reliability, and durability prediction of wet layup carbon/epoxy used in external strengthening," Composites Part B: Engineering, vol. 38, no. 1, pp. 10-23, 2007.

[7] Z. Wu, Y. J. Kim, H. Diab, and X. Wang, "Recent developments in long-term performance of FRP composites and FRP-concrete interface," Advances in Structural Engineering, vol. 13, no. 5, pp. 891-903, 2010.

[8] M. A. G. Silva and H. Biscaia, "Environmental effects on bond of GFRP external reinforcement to RC beams," in Proceeding of the 8th International Symposium on Fiber Reinforced Polymer Reinforcement for Concrete Structures, FRPRCS-8, University of Patras, Patras, Greece, July 2007.

[9] M. I. Kabir, B. Samali, and R. Shrestha, "Fracture Properties of CFRP-Concrete Bond Subjected to Three Environmental Conditions," Journal of Composites for Construction, vol. 20, no. 4, Article ID 4016010, 2016.

[10] Y. J. Kim, M. Hossain, and Y. Chi, "Characteristics of CFRPconcrete interface subjected to cold region environments including three-dimensional topography," Cold Regions Science and Technology, vol. 67, no. 1-2, pp. 37-48, 2011.

[11] Y. J. Kim, M. Hossain, and J. Zhang, "A probabilistic investigation into deterioration of CFRP-concrete interface in aggressive environments," Construction and Building Materials, vol. 41, pp. 49-59, 2013.

[12] H. C. Biscaia, M. A. G. Silva, and C. Chastre, "An experimental study of GFRP-to-concrete interfaces submitted to humidity cycles," Composite Structures, vol. 110, pp. 354-368, 2014.

[13] J.-L. Wang and S. Amidi, "Subcritical debonding of FRP-toconcrete bonded interface under synergistic effect of load, moisture, and temperature," Mechanics of Materials, vol. 92, pp. 80-93, 2016.

[14] Y. V. Lipatov, S. I. Gutnikov, M. S. Manylov, E. S. Zhukovskaya, and B. I. Lazoryak, "High alkali-resistant basalt fiber for reinforcing concrete," Materials and Corrosion, vol. 73, pp. 6066, 2015.

[15] P. Feng, L. Hu, P. Qian, and L. Ye, "Compressive bearing capacity of CFRP-aluminum alloy hybrid tubes," Composite Structures, vol. 140, pp. 749-757, 2016.

[16] B. Benmokrane, F. Elgabbas, E. A. Ahmed, and P. Cousin, "Characterization and Comparative Durability Study of Glass/ Vinylester, Basalt/Vinylester, and Basalt/Epoxy FRP Bars," Journal of Composites for Construction, vol. 19, no. 6, Article ID 04015008, 2015.

[17] J. Xu, H. Kolstein, and F. S. K. Bijlaard, "Moisture diffusion and hygrothermal aging in pultruded fibre reinforced polymer composites of bridge decks," Materials and Design, vol. 37, pp. 304-312, 2012.

[18] H. Toutanji and M. Saafi, "Durability studies on concrete columns encased in PVC-FRP composite tubes," Composite Structures, vol. 54, no. 1, pp. 27-35, 2001.

[19] Y. Chen, J. F. Davalos, I. Ray, and H. Y. Kim, "Accelerated aging tests for evaluations of durability performance of FRP reinforcing bars for concrete structures," Composite Structures, vol. 78, no. 1, pp. 101-111, 2007.

[20] P. Boer, L. Holliday, and T. H.-K. Kang, "Independent environmental effects on durability of fiber-reinforced polymer wraps in civil applications: a review," Construction and Building Materials, vol. 48, pp. 360-370, 2013.
[21] J. U. N. Wang, H. O. T. A. Gangarao, R. Liang, and W. Liu, "Durability and prediction models of fiber-reinforced polymer composites under various environmental conditions: A critical review," Journal of Reinforced Plastics and Composites, vol. 35, no. 3, pp. 179-211, 2016.

[22] J. J. Myers, S. S. Murthy, and F. Micelli, "Effect of combined environmental cycles on the bond of FRP sheets to concrete," in Proceedings of the 2001 International Conference-Composites in Construction, Porto, Portugal, October 2001.

[23] K. K. Mahato, K. Dutta, and B. C. Ray, "High-temperature tensile behavior at different crosshead speeds during loading of glass fiber-reinforced polymer composites," Journal of Applied Polymer Science, vol. 134, no. 16, Article ID 44715, 2017.

[24] J. Wang, H. GangaRao, R. Liang, D. Zhou, W. Liu, and Y. Fang, "Durability of glass fiber-reinforced polymer composites under the combined effects of moisture and sustained loads," Journal of Reinforced Plastics and Composites, vol. 34, no. 21, pp. 17391754, 2015.

[25] ASTM D638-10, "Standard Test Method for Tensile Properties of Plastics," in Proceedings of the American Society for Testing and Materials, January 2010.

[26] M. S. Sciolti, M. Frigione, and M. A. Aiello, "Wet lay-up manu factured FRPs for concrete and masonry repair: influence of water on the properties of composites and on their epoxy components," Journal of Composites for Construction, vol. 14, no. 6, pp. 823-833, 2010.

[27] B. Ghiassi, G. Marcari, D. V. Oliveira, and P. B. Lourenço, "Water degrading effects on the bond behavior in FRP-strengthened masonry," Composites Part B: Engineering, vol. 54, no. 1, pp. 1119, 2013.

[28] S. P. Sonawala and R. J. Spontak, "Degradation kinetics of glass-reinforced polyesters in chemical environments: Part II. Organic solvents," Journal of Materials Science, vol. 31, no. 18, pp. 4757-4765, 1996.

[29] M. A. Abanilla, Y. Li, and V. M. Karbhari, "Durability characterization of wet layup graphite/epoxy composites used in external strengthening," Composites Part B: Engineering, vol. 37, no. 2-3, pp. 200-212, 2005.

[30] B. Abdel-Magid, S. Ziaee, K. Gass, and M. Schneider, "The combined effects of load, moisture and temperature on the properties of E-glass/epoxy composites," Composite Structures, vol. 71, no. 3-4, pp. 320-326, 2005.

[31] P. Marru, V. Latane, C. Puja, K. Vikas, P. Kumar, and S. Neogi, "Lifetime estimation of glass reinforced epoxy pipes in acidic and alkaline environment using accelerated test methodology," Fibers and Polymers, vol. 15, no. 9, pp. 1935-1940, 2014. 

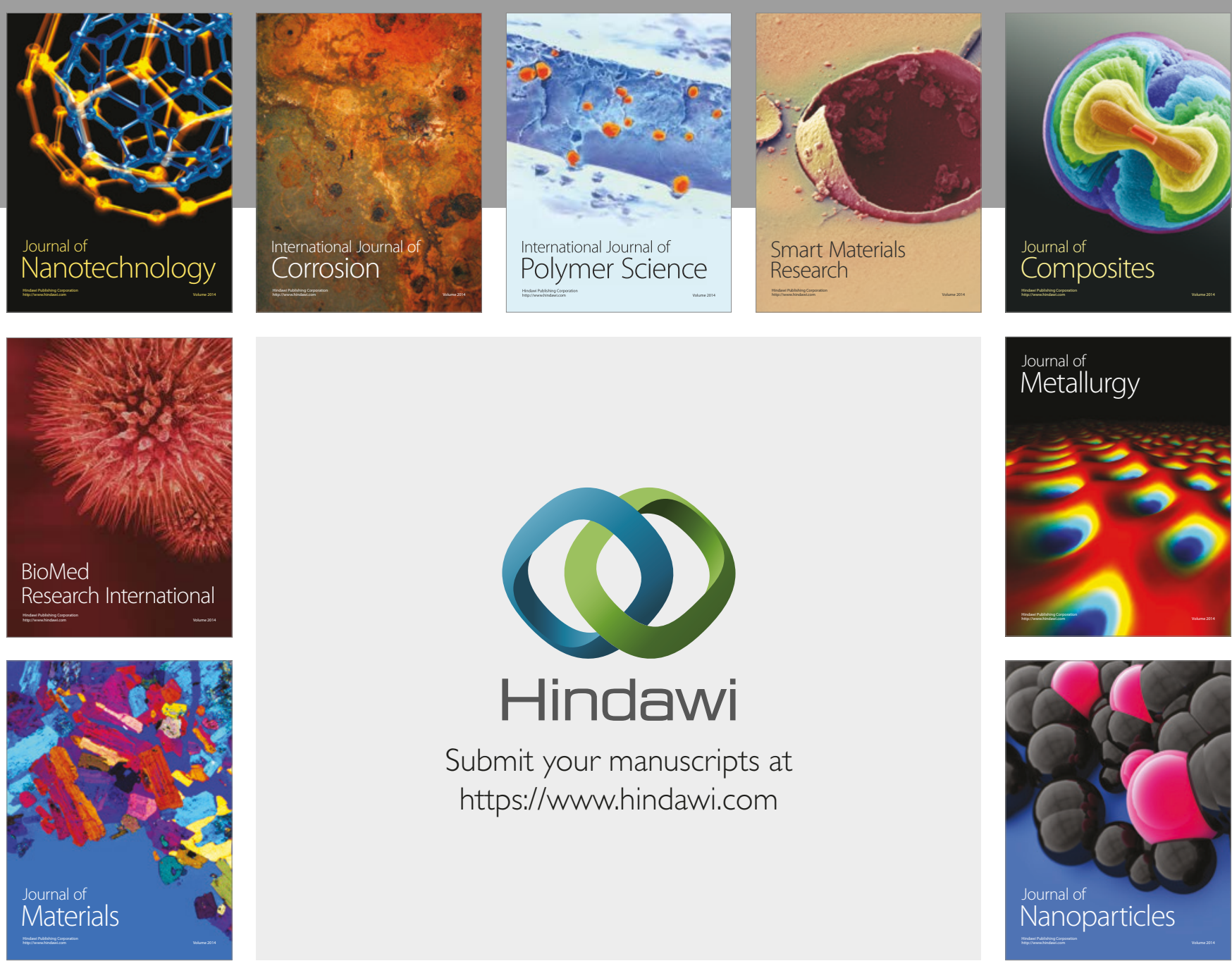

\section{Hindawi}

Submit your manuscripts at

https://www.hindawi.com
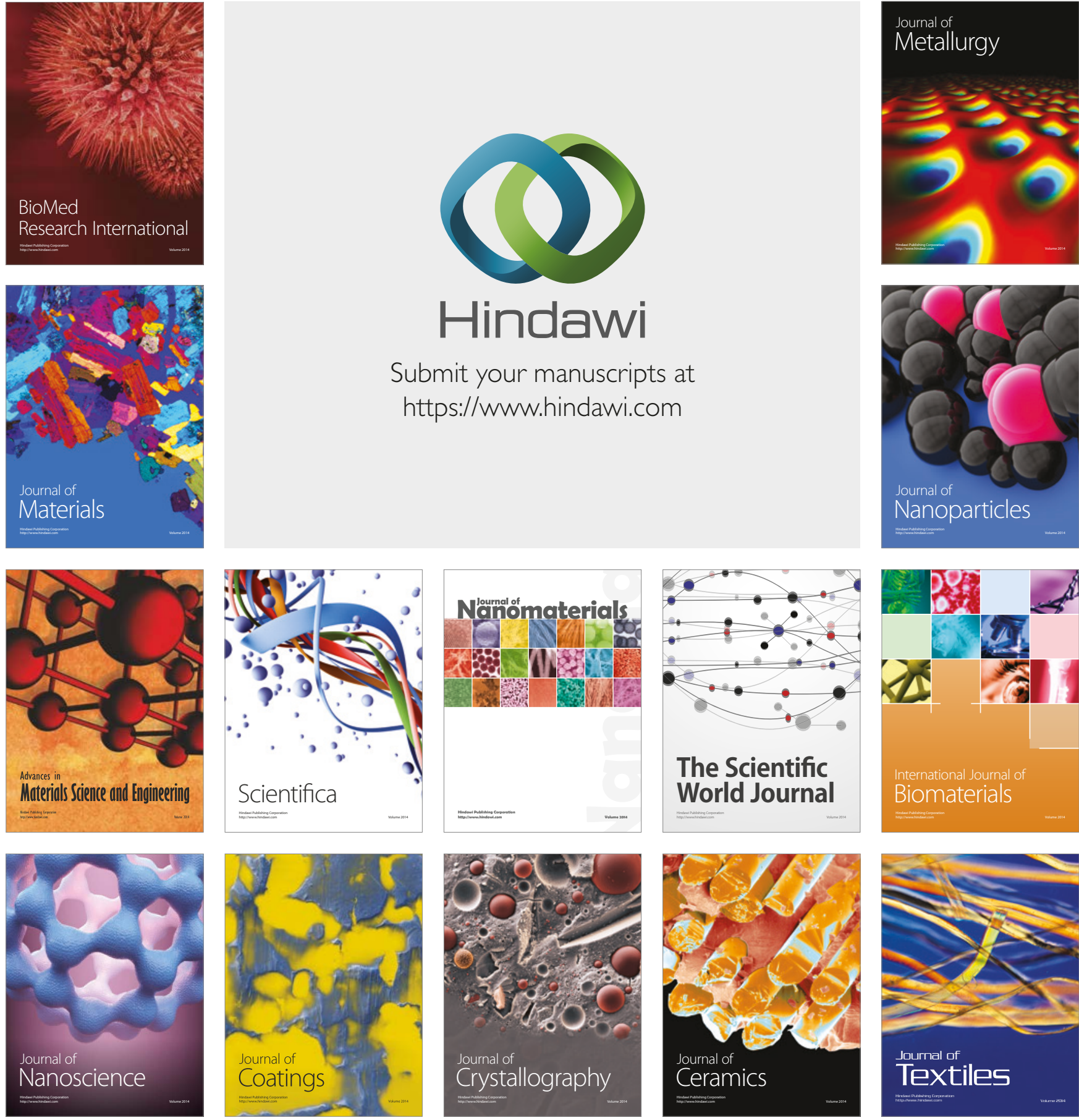

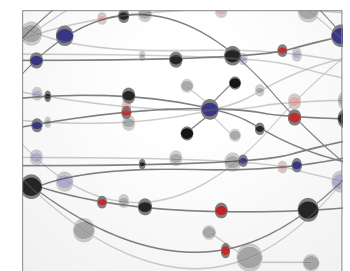

The Scientific World Journal
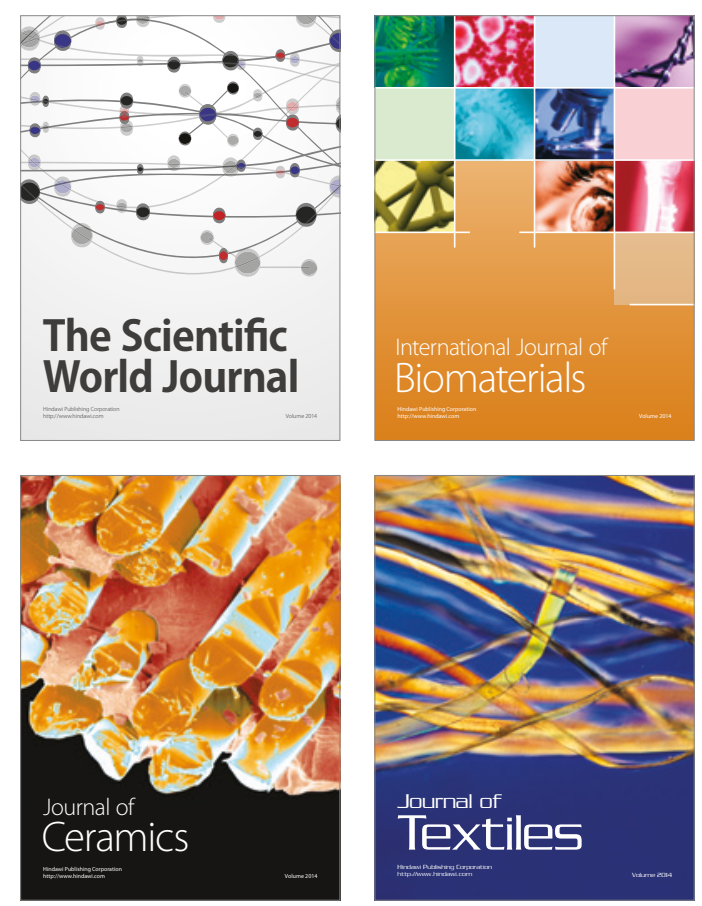